\title{
Innovative use of digital fire to improve fire-fighting skills in a tertiary care hospital
}

\section{Ranjit Bhogal, Anil Gupta, Arun Kumar Aggarwal', Ashok Kumar}

Department of Hospital Administration, Postgraduate Institute of Medical Education and Research, ${ }^{1}$ Department of Community Medicine, School of Public Health, Postgraduate Institute of Medical Education and

Research, Chandigarh, India

Address for the Correspondence:

Dr. Arun Kumar Aggarwal,

School of Public Health,

Postgraduate Institute of Medical

Education and Research,

Chandigarh - 160 012, India.

E-mail: aggak63@gmail.com

\section{Access this article online}

Website: www.ijmedph.org

DOI: $10.4103 / 2230-8598.165981$

Quick response code:

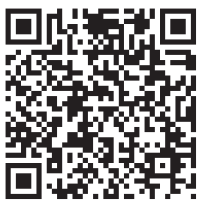

Context: Hospitals are prone to fire. Hospital fire management is also tricky as sick patients are not aware about the surroundings, and also they cannot move of their own. Thus, hospital staff is primarily responsible for taking appropriate and timely measures in case of the hospital fire. However, hospital staff lack knowledge and skills about fire safety. In addition, it is extremely difficult to organize fire drills in a hospital setting for skill improvement. Aims: To conduct fire drills using "digital fire" for skill building and compare it with the usual training method of using information booklets. Settings and Design: Interventional study using before and after study design using alternate interventions in hospital setting. Materials and Methods: Hospital staff (staff nurses, security personnel and hospital attendants) was divided into two groups of 119 persons in each group. Group I was administered information booklets and group II was given lecture demonstration and digital fire drill. Pretest and posttest knowledge and skill assessment was done in both the groups. Statistical Analysis Used: Mean score comparison, pre- and post-intervention, in the two intervention groups, using $t$-test. Results: Increase in the knowledge scores was significant and similar with both the interventions. However, increase in skill score was more with intervention II. Conclusions: Whereas, information booklets should be distributed and made available to all, it should be mandatory to have skill building demonstration sessions periodically in the hospitals. Digital fire can be used conveniently and effectively.

Key words: Digital fire, fire safety, hospital, knowledge, skills, training method

\section{INTRODUCTION}

Fire in the hospitals is generally man-made disaster. Hospitals use many electrical equipment, medical gases and inflammable liquids often together at the single point of use. Any error anywhere can spark the fire. Hospital population is also more vulnerable to the adverse impact of fire as sick population cannot move at its own. Worldwide there were 21 fire disasters in hospitals in which 1334 persons lost life. ${ }^{[1]}$ About 90 people died at one fire incident in an Indian hospital recently. ${ }^{[2]}$

Lack of knowledge and skills of hospital staff in dealing with fire is one of the leading factors contributing to the loss of life. As per the National Building Code 2005 regulations at least $40 \%$ of the occupants should be trained in conducting proper evacuation, and in the operation of systems and equipment, and other fire safety provisions in the building. ${ }^{[3]}$ Hospital buildings are distinct from other buildings because patients are not acquainted with the premises, are dependent on hospital staff and cannot move at their own during such disasters. Therefore, the hospital staff should be well trained in evacuation procedures. ${ }^{[4]}$ In many cases, the loss of life is due to lack of knowledge and actions of own during fire..$^{[5,6]}$

There is not much literature on the training methodologies on fire management for hospital staff. Some researchers have assessed the computer based simulations with one to one training session..$^{7,8]}$ But not all individuals learn in the same way. ${ }^{[4]}$ As workers lack basic style in reading, writing and arithmetic, different options of training have to be provided. ${ }^{[9]}$ Imparting training to improve skills related to fire disaster management is particularly tricky and difficult. It is not known whether simply providing information through well designed written material can improve the knowledge and skills on fire management or some sort of presentations/demonstrations and drills are required for skill 
building. Therefore, this study was carried out to assess which of the following two training methods was better in improving knowledge and skills of the hospital staff regarding fire safety system?

(1) Information booklets and

(2) Information booklet with lecture and demonstrations using digital fire.

\section{MATERIALS AND METHODS}

This was a cross-sectional study carried out in a tertiary care hospital of Northern India. Nursing staff, hospital attendants, and security personnel were included in the study as they are responsible for the security of the patients/attendants in the hospital. Sample size in each category of nurses, hospital attendants, and security persons was calculated with the assumption that knowledge levels with the first intervention (information booklets) will be around 50\%. At 95\% confidence interval, $80 \%$ power, and knowledge levels with second intervention (information booklet with lectures and demonstration with digital fire) around $70 \%$, odds ratio of 2.3 , sample size came out to be 206, using EPI Info 7 software (CDC Atlanta, GA, 2011) for epidemiological studies. A total of 250 subjects were selected for the study to account for nonparticipation and dropout from the follow-up assessments.

There were total of 1058 staff nurses, 126 hospital attendants and 275 security staff posted in the hospital in all the three shifts. Probability proportional to size sampling was done to select the sample from the three strata. Accordingly $70 \%$ sample was taken from the nurses, $10 \%$ from hospital attendants and another $20 \%$ from security staff. Total sample size came out to be 175 nurses, 25 hospital attendants, and 50 security personnel. The list of staff on duty was obtained from the concerned officials and calculated sample size was sampled considering the duty roster to avoid any disturbance to patient care area. The samples were further divided into batches of maximum 30 persons in each batch. There were around 10 batches to cover the calculated sample size.

\section{Study tools}

\section{Tool development}

A pretested questionnaire was administered to the hospital staff to assess their knowledge and skills.

For intervention I, an information booklet was developed incorporating information on the basic instructions for evacuating the patients, use of fire extinguishers, and important telephone numbers for use in case of fire emergency or any other emergency.

For intervention II, a power point presentation was prepared. Digital fire videos were downloaded from the internet from the material available in the public domain. ${ }^{[10]}$ This video was used for skill evaluation and skill build-ups on use of fire extinguishers.

\section{Interventions}

The sample population was divided into two equal groups proportionally. Baseline survey questionnaire was administered to all the participants of the two groups. The first group was given a booklet (intervention-I). Second group was administered booklet with the interactive session (intervention-II) involving hand on practice with the fire extinguishers.

\section{Collection of data}

The selected staff was briefed about the objectives of the study, and their consent was obtained. They were also ensured about the confidentiality of the data. They were given same pre- and postintervention questionnaire. The group I participants were given with pretest questionnaire and fire safety information booklet. They were given some time to read and understand it. Queries if any were responded to. After a week, this group was called again in sub groups of 30 each, and was given the same questionnaire (posttest). After that, the class room training with hand on practice on fire extinguishers was given for ethical reasons. The group II was called for class room training with hand on practice for fire extinguishers in sub groups at the same venue. After doing pretest assessment, power point presentation was done. After that artificial fire was created digitally, and participants were asked to use the fire extinguishers on the screen.

\section{Consent and confidentiality}

Prior consent was obtained from all participants in the study. Identity of the participants in the study was kept confidential, and they had the right to refuse participation.

\section{Data analysis}

Responses to multiple choice questions were marked as "correct" or "incorrect" and the total number of "correct" responses was calculated. Knowledge and skill items were converted into scores. Equal weightage was given to each item. Consolidated pre- and posttest mean knowledge scores were calculated for each intervention group. Change in mean scores pre- and post-intervention were calculated for each of the two intervention groups. Scores of two groups were also compared at pre- and post-intervention. If " $\mathrm{X}$ " denotes intervention I and ' $\mathrm{Y}$ " denotes intervention II, and number 1 denotes preintervention score and number 2 denotes postintervention score, then following comparisons were done for testing statistical significance by applying t-test: X1 and X2, Y1 and Y2, X1 and Y1, $\mathrm{X} 2$ and $\mathrm{Y} 2$ [Table 1].

\section{Ethics committee permission}

The Institute Ethics Committee has given the approval for the research work vide-letter number 09/PGI-08/7355-56 dated 0904-2013.

\section{RESULTS}

The study population consisted of 238 participants-159 females and 73 males, who completed pre- and post-test questionnaire for intervention I and II. The age range was from 21 to 59 years 
for both the interventions. The mean age was 37 years (standard deviation $[S D]=11.4)$ for intervention $I$ and 32 years $(S D=10.1)$ for intervention II.

A total of 226 persons mentioned their service experience. In intervention I group, there were $26(23.2 \%)$ participants with $<5$ years of experience, $41(36.6 \%)$ with $5-15$ years and $45(40.2 \%)$ had $>15$ years of experience. In intervention II group, there were $52(45.6 \%)$ participants with $<5$ years experience, $44(38.6 \%)$ with $15-30$ years of experience and 18 (15.8\%) had $>15$ years of experience.

Of the participants who mentioned their educational qualification, there were $34(35.7 \%)$ undergraduate, 20 (32.8\%) graduate and $7(11.5 \%)$ postgraduate in intervention I group. Whereas in intervention II group, there were 29 (48.3\%) undergraduate, 26 $(43.3 \%)$ graduates and $5(8.3 \%)$ postgraduates.

The mean pretest knowledge score was 13.2 in intervention I and 13.0 in intervention II. The mean pretest knowledge scores were not significantly different in the two intervention groups $(P=0.368)$. The mean posttest knowledge score was 16.6 in intervention I and 17.1 in intervention II. This was also not significantly different in the two groups $(P=0.068)$. Both groups showed significantly high increase in the knowledge scores $(P<0.0001)$. The mean knowledge scores increased from 13 to 16 in group $I(P<0.01)$ and from 13 to 17 in group II $(P<0.01)$.

Mean pretest skill score was 2.88 for intervention I and was 2.9 for intervention II. Mean posttest skill score was 3.26 for intervention I and 4.72 for intervention II. Gain in skill was significant in both groups but the gain was significantly more in intervention II group $(P<0.001)$ [Table 1].

Further explorative analysis was done to understand differentials in the knowledge scores with the two interventions with respect to the age-group, gender, occupation, and number of years in the service. It was observed that for intervention I, increase in knowledge was highest (17.08) in $>45$ years age group. Females had better pre- and post-score mean knowledge than the male counter parts. In intervention I, group with $<5$ years of experience had the highest pretest knowledge score of 13.85 and the group with $>15$ years of experience had the lowest pretest knowledge of score of 12.56. However, posttest knowledge mean score was 17.09 (16.59-17.58) in former group compared to the mean score of $15.92(15.24-16.61)$ in the later group. As per $95 \%$ confidence interval, there was significant gain in skill score in intervention II in all the groups/categories, but there is no significant change seen in the skill score in intervention I except among the participants who were graduates.

Item wise change in knowledge and skill scores is shown in Table 2. Participants scored above $80 \%$ in 6-7 items before intervention. They knew about the common causes of fire, use of smoke alarms and fire alarms, phone numbers of the fire control room, and who should be evacuated first in case of fire, etc. However, their knowledge on the specifics like the fire routes, location of fire control room, types of fire extinguishers, how to exit, and what are steps for fire management etc., was low. Intervention I improved knowledge for all domains but the one for types of fire extinguishers. Intervention II could also improve knowledge for all the items except the one on what should be done first in case of fire.

\section{DISCUSSION}

Both the training methods were equally effective in raising the knowledge scores on fire safety, however second training method was more effective in raising the skill scores on fire management. Age, occupation and experience of participants were associated with the change in the knowledge scores. Participants in the higher age groups and with more experience had higher scores with the first training method. However, the younger participants benefitted more with lecture and demonstration. This may be because senior persons having more responsibilities both at work and for their families were finding it difficult to sit in the class rooms. At the same time, they were comfortable in reading and understanding the written information booklets. Younger participants on the other hand were more attentive with lecture demonstration mode and were keen to participate. In skill development; it was observed that intervention II had a marked impact across all predictors. Both methods were found useful for training and improving awareness about the firefighting mechanism.

\section{CONCLUSION}

Fire management requires execution of knowledge. In such disasters, where time to act is limited and chances of getting panic are very high, appropriate skills are of utmost importance. Thus, although information booklet can increase the knowledge, demonstrations of fire management through innovative digital fires should be built in the routine training programs.

\begin{tabular}{|c|c|c|c|c|c|c|c|}
\hline Category & $n$ & Prescore mean & $95 \% \mathrm{Cl}$ & Postscore mean & $95 \% \mathrm{Cl}$ & Change & $95 \% \mathrm{Cl}$ \\
\hline \multicolumn{8}{|l|}{ Intervention I } \\
\hline Knowledge & 119 & 13.2 & $12.6-13.7$ & 16.6 & $16.3-16.9$ & 3.44 & $2.9-3.9$ \\
\hline Skill & 119 & 2.88 & 2.5-3.1 & 3.26 & $3.0-3.5$ & 0.39 & $0.2-0.5$ \\
\hline \multicolumn{8}{|l|}{ Intervention II } \\
\hline Knowledge & 119 & 13.0 & $12.5-13.5$ & 17.1 & $16.7-17.4$ & 4.04 & $3.5-4.5$ \\
\hline Skill & 119 & 2.9 & 2.6-3.2 & 4.7 & $4.5-4.8$ & 1.7 & $1.4-2.1$ \\
\hline
\end{tabular}

$\mathrm{Cl}=$ Confidence interval 


\begin{tabular}{|c|c|c|c|c|c|c|c|c|}
\hline \multirow[t]{2}{*}{ Questions } & \multicolumn{4}{|c|}{ Intervention I } & \multicolumn{4}{|c|}{ Intervention II } \\
\hline & Pretest & Percentage & Posttest & Percentage & Pretest & Percentage & Posttest & Percentage \\
\hline Most common cause of fire in hospitals & 107 & 89.9 & 117 & 98.3 & 104 & 88.1 & 112 & 94.9 \\
\hline Symbol indicating fire escape route & 74 & 62.2 & 101 & $84.9^{*}$ & 84 & 70.6 & 111 & $94.9^{*}$ \\
\hline $\begin{array}{l}\text { Fire route in a ward should remain open all } \\
\text { the time }\end{array}$ & 60 & 51.3 & 83 & $70.9^{*}$ & 81 & 68.1 & 111 & $93.2^{*}$ \\
\hline Use of smoke alarms/detectors in a building & 104 & 90.4 & 112 & 97.4 & 109 & 94.2 & 117 & 99.2 \\
\hline Picture of fire alarm call point & 111 & 93.3 & 118 & 99.2 & 111 & 94.1 & 117 & 99.2 \\
\hline Phone number of main fire control room & 109 & 92.4 & 115 & 97.5 & 115 & 96.6 & 118 & 99.2 \\
\hline $\begin{array}{l}\text { Location of main fire control room in the } \\
\text { hospital }\end{array}$ & 75 & 65.2 & 90 & 78.3 & 66 & 55.5 & 110 & $92.4^{*}$ \\
\hline Type of fire extinguisher in the picture & 55 & 48.7 & 78 & 69 & 61 & 51.3 & 109 & $91.6^{*}$ \\
\hline Acronym RACE: Rescue & 55 & 47.8 & 106 & $92.2^{*}$ & 45 & 38.5 & 102 & $87.2^{*}$ \\
\hline Acronym RACE: Alarm & 53 & 44.9 & 103 & $87.3^{*}$ & 50 & 42 & 90 & $75.6^{*}$ \\
\hline Acronym RACE: Confine & 37 & 31.6 & 94 & $80.3^{*}$ & 43 & 36.4 & 102 & $86.4^{*}$ \\
\hline Acronym RACE: Extinguish & 41 & 34.7 & 98 & $83.1^{*}$ & 47 & 39.5 & 99 & $83.2^{*}$ \\
\hline How to exit in case fire accumulates in ward & 81 & 68.6 & 105 & 89 & 85 & 72 & 109 & $92.4^{*}$ \\
\hline Whom to evacuate first in case of fire & 114 & 97.4 & 116 & 99.1 & 111 & 96.5 & 115 & 97.5 \\
\hline $\begin{array}{l}\text { What should be done in case a patient is left } \\
\text { inside during evacuation }\end{array}$ & 98 & 83.1 & 102 & 86.4 & 102 & 86.4 & 118 & 99.2 \\
\hline $\begin{array}{l}\text { What should the first thing to be done in } \\
\text { case of fire }\end{array}$ & 80 & 69 & 99 & 85.3 & 75 & 63 & 94 & 79 \\
\hline $\begin{array}{l}\text { Where to shift the patients most immediately } \\
\text { in case of fire }\end{array}$ & 82 & 69.5 & 96 & 81.4 & 70 & 58.8 & 97 & $81.5^{*}$ \\
\hline Action to be taken to confine the fire & 75 & 64.7 & 112 & 96.6 & 79 & 66.9 & 107 & $90.7^{*}$ \\
\hline $\begin{array}{l}\text { Outcome if water-based fire extinguisher is } \\
\text { used on fire involving grease or electrical items }\end{array}$ & 91 & 96.5 & 116 & 97.5 & 81 & 68.1 & 107 & 87.9 \\
\hline
\end{tabular}

\section{Limitations}

While doing skill assessment, entire group was observing and providing technical hints to the performing person. Thus, future studies may be done to assess the persons individually to filter the group effect. However, in hospital setting where the mandate is to improve the skills, same method can be used.

\section{REFERENCES}

1. Cavallini M, Papagni MF, Baruffaldi Preis FW. Fire disasters in the twentieth century. Ann Burns Fire Disasters 2007;20:101-3.

2. 89 Dead in Kolkata Hospital-Fire. The Hindustan Times; 2011. Available from: http://www.hindustantimes.com/India-news/Kolkata// Article1-79821.aspx. [Last accessed on 2012 Apr 10].

3. National Building Code of India Part 4 Fire and Life Safety. Available from: http://www.ndrfandcd.gov.in/WriteReadData/userfiles/file/F03.pdf. [Last accessed on 2013 Jun 27].

4. Walker BL, Harrington SS. Can nursing facility staff with minimal education be successfully trained with computer-based training? Nurse Educ Today 2004;24:301-9
5. Hwang V, Duchossois GP, Garcia-Espana JF, Durbin DR. Impact of a community based fire prevention intervention on fire safety knowledge and behavior in elementary school children. Inj Prev 2006;12:344-6.

6. Calrke BF, Birkey M. Fire safety in Dwellings and public building center for the fire research. Washinton, DC: National Bureau of Standards; 1981.

7. Harrington SS, Walker BL. The effects of computer-based fire safety training on the knowledge, attitudes, and practices of caregivers. J Contin Educ Nurs 2009;40:79-86.

8. Harrington SS, Walker BL. Is computer-based instruction an effective way to present fire safety training to long-term care staff? J Nurses Staff Dev 2003;19:147-54.

9. Hess VT. Literacy and learning for hospital employees. J Nurses Staff Dev 1998;14:143-6.

10. Burning Fire Log; 2011. Available from: http://www.youtube.com/ watch?v=BLmwmX-mni8\#aid=P9J1Xn-N8bi potential. [Last accessed on 2012 Apr 10].

How to cite this article: Bhogal R, Gupta A, Aggarwal AK, Kumar A. Innovative use of digital fire to improve fire-fighting skills in a tertiary care hospital. Int J Med Public Health 2015;5:336-9.

Source of Support: Nil, Conflicts of Interest: None declared. 